\title{
Impact of model resolution on simulating the water vapor transport through the central Himalayas: implication for models' wet bias over the Tibetan Plateau
}

\author{
Changgui Lin ${ }^{1}\left[\right.$ Deliang Chen ${ }^{1} \cdot \mathrm{Kun} \mathrm{Yang}^{2,3} \cdot$ Tinghai Ou$^{1}$
}

Received: 29 August 2017 / Accepted: 7 January 2018 / Published online: 19 January 2018

(c) The Author(s) 2018. This article is an open access publication

\begin{abstract}
Current climate models commonly overestimate precipitation over the Tibetan Plateau (TP), which limits our understanding of past and future water balance in the region. Identifying sources of such models' wet bias is therefore crucial. The Himalayas is considered a major pathway of water vapor transport (WVT) towards the TP. Their steep terrain, together with associated small-scale processes, cannot be resolved by coarse-resolution models, which may result in excessive WVT towards the TP. This paper, therefore, investigated the resolution dependency of simulated WVT through the central Himalayas and its further impact on precipitation bias over the TP. According to a summer monsoon season of simulations conducted using the weather research forecasting (WRF) model with resolutions of 30,10, and $2 \mathrm{~km}$, the study found that finer resolutions (especially $2 \mathrm{~km}$ ) diminish the positive precipitation bias over the TP. The higher-resolution simulations produce more precipitation over the southern Himalayan slopes and weaker WVT towards the TP, explaining the reduced wet bias. The decreased WVT is reflected mostly in the weakened wind speed, which is due to the fact that the high resolution can improve resolving orographic drag over a complex terrain and other processes associated with heterogeneous surface forcing. A significant difference was particularly found when the model resolution is changed from 30 to $10 \mathrm{~km}$, suggesting that a resolution of approximately $10 \mathrm{~km}$ represents a good compromise between a more spatially detailed simulation of WVT and computational cost for a domain covering the whole TP.
\end{abstract}

Keywords Wet bias · Water vapor transport $\cdot$ Resolution dependency $\cdot$ Tibetan Plateau $\cdot$ Himalayas

\section{Introduction}

The Tibetan Plateau (TP), the highest and most extensive highland in the world, is considered the water tower of Asia (e.g., Xu et al. 2008) because it hosts the headwaters of many major Asian river systems (Su et al. 2016). Precipitation changes over the TP are critical to glacier mass balance, river runoff and local ecology (e.g., Yang et al. 2011; Yao

Changgui Lin

mapulynn@gmail.com

1 Regional Climate Group, Department of Earth Sciences, University of Gothenburg, Box 460, 40530 Gothenburg, Sweden

2 Ministry of Education Key Laboratory for Earth System Modeling and Center for Earth System Science, Tsinghua University, Beijing 100875, China

3 CAS Center for Excellence in Tibetan Plateau Earth Sciences, Beijing 100101, China et al. 2012; Shen et al. 2015). This, in turn, has significant implications for securing Asia's water tower and the wellbeing of a large portion of the world's population downstream.

Numerical models provide the best tools for projecting future climate changes, and precipitation is one of the most important variables to be delivered as it drives hydrological processes. However, the majority of global climate models (GCMs) participating in the Fifth Phase of the Coupled Model Inter-comparison Project (CMIP5) significantly overestimate precipitation over the TP (e.g., Su et al. 2013; Mehran et al. 2014; Mueller and Seneviratne 2014). Regional climate models (RCMs) with a coarse resolution do not reduce the wet bias (referred to positive bias in precipitation herein) much (e.g., Ji and Kang 2013; Maussion et al. 2014; Gao et al. 2015; Ma et al. 2015). Determining its sources, therefore, is crucial for the performance improvement of current models in this region, one of the probable "tipping points" in the global climate system (Lenton et al. 2008). 
The wet bias may be attributed to issues with the dynamical core, imperfect errors produced by parameterization schemes, and/or coarse horizontal resolution. The computational errors of pressure gradient force at the lowest model levels induced by the terrain-following coordinate (Danard et al. 1993) and the decoupling between advection and condensation processes (Codron and Sadourny 2002) are noticed as probable factors contributing to the overestimation of orographic precipitation. Apart from errors in microphysics and cumulus schemes, which directly represent the physical processes responsible for precipitation, inappropriate land surface schemes may also disgrace contribute to precipitation errors by producing an unrealistic local recycling of moisture (Gao et al. 2017). Due to the coarse resolution, climate models cannot resolve the steep terrain (like the Himalayas) and fail to capture regional-scale processes, which may affect the simulation of water vapor transport (WVT) and ultimately precipitation.

Efforts including advection scheme modification have been made to mitigate the precipitation bias on the steep edge of the TP in GCMs (Yu et al. 2015; Zhang and Li 2016). Nevertheless, the resolution dependency of WVT in a model remains to be clarified, which represents an interesting and feasible starting point of departure to investigate the potential sources of wet bias over the TP by considering the following facts: (1) the TP's complex terrain (especially the margin area) is poorly represented by coarse-resolution models; (2) positive systematic errors in precipitable water (PW) has been confirmed in the reanalyses for the southern TP (Wang et al. 2017), implying an excessive amount of water vapor flowing into the TP in climate models; and, (3) fact (2) may lead to an unrealistic reaction of hydroclimate processes in a model, hindering the assessment of precipitation bias brought from parameterization schemes.

Although RCMs used for the TP typically have resolutions of a few tens $\mathrm{km}$, most of them can offer higher resolutions which provide more accurate surface forcing of regional climate processes, such as those associated with topography, land-water contrasts and heterogeneous surface cover. Numerous studies illustrated that increasing resolution could improve many simulated features of local climate processes and variables (e.g., Sato et al. 2008; Chin et al. 2010; Norris et al. 2016; Mughal et al. 2017). This demonstrates the potential for a more realistic simulation of hydroclimate over the region with a higher resolution. Recently, studies (Collier and Immerzeel 2015; Karki et al. 2017) have shown that high resolution indeed brings added value to the simulation of precipitation over the complex terrain of the central Himalayas. With regard to atmospheric water supply for summertime precipitation over the TP from the South Asian monsoon, the Himalayas are recognized as a major pathway for WVT from the Indian Mainland to the TP (e.g., Tian et al. 2007; Feng and Zhou 2012; Zhang et al. 2017).
The steep terrain of the Himalayas is generally considered a barrier for WVT, whereas there are many meridional canyons in this region that may function as vapor channels (Bookhagen and Burbank 2010). Thus, a sufficient model resolution (being available to describe the aforesaid terrain features) becomes critical to realistically simulate WVT over the complex terrain in the Himalayas. Curio et al. (2015) discussed the difference of WVT towards the TP between the two resolutions, 30 and $10 \mathrm{~km}$, of the High Asia Refined (HAR) data (Maussion et al. 2014). Nevertheless, to the best of our knowledge, no study has yet evaluated the added value with respect to WVT from a fine resolution model of convection permitting and kilometer terrain resolving so far. Employing the Weather Research Forecasting (WRF) model (designed as the next-generation mesoscale simulation system for use across a broad range of weather forecasts and idealized research applications) (Skamarock et al. 2008), this paper aims to address the resolution dependency of simulated WVT over the Himalayas and its further impact on precipitation bias over the TP.

\section{Methodology}

\subsection{Modeling design}

\subsubsection{Study region and model domains}

The Advanced Research WRF (ARW) version 3.7.1, which features state-of-the-art numeric and numerous physical parameterizations and is suitable for simulating across a variety of horizontal and vertical scales, is utilized in this study. Three one-way nested domains D1, D2, and D3 used by the WRF were configured at 30,10, and $2 \mathrm{~km}$ horizontal grid spacing, respectively (Fig. 1a). D1 (the outer domain) contains the complete body of the vast Asian highlands. The Bay of Bengal and parts of the Arabian Sea, which are considered the moisture sources of prevailing monsoonal precipitation over the TP (e.g., Tian et al. 2007; Feng and Zhou 2012; Zhang et al. 2017), are also covered in D1. D2 (the middle domain) spans from the moister Ganges Plain to the southern part of the TP that is influenced by the monsoon during summer, with the Himalayan range centered. It includes two major pathways of water vapor transport associated with the South Asian monsoon (e.g., Tian et al. 2007), i.e., one crossing over the Himalayas and the other penetrating into the TP through the Brahmaputra River. D3 (the inner domain) is situated in the central Himalayas. It comprises the slopes of the central Himalayas and a part of the southern TP. Further, it features very complex terrain including several high mountains and low valleys, e.g., Mt. Everest, Mt. Kanchenjunga, and the Yadong Valley. 


\section{(a)}

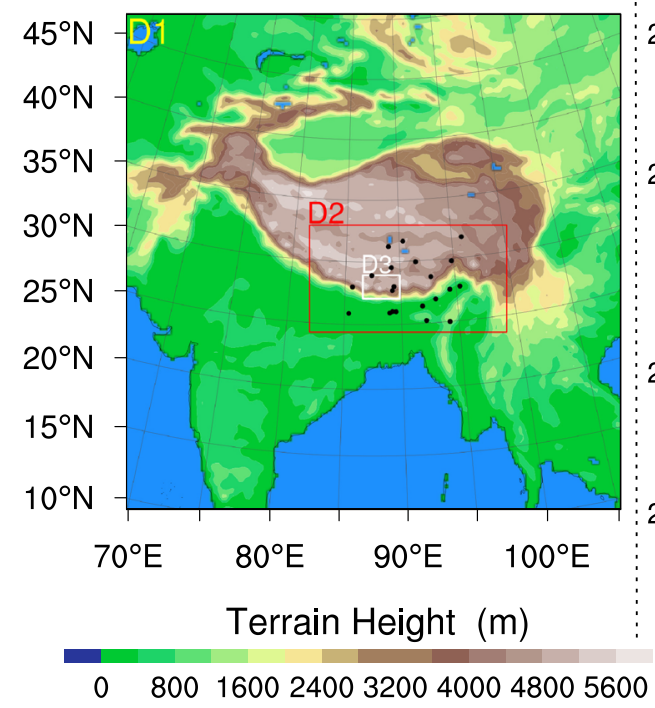

(b)

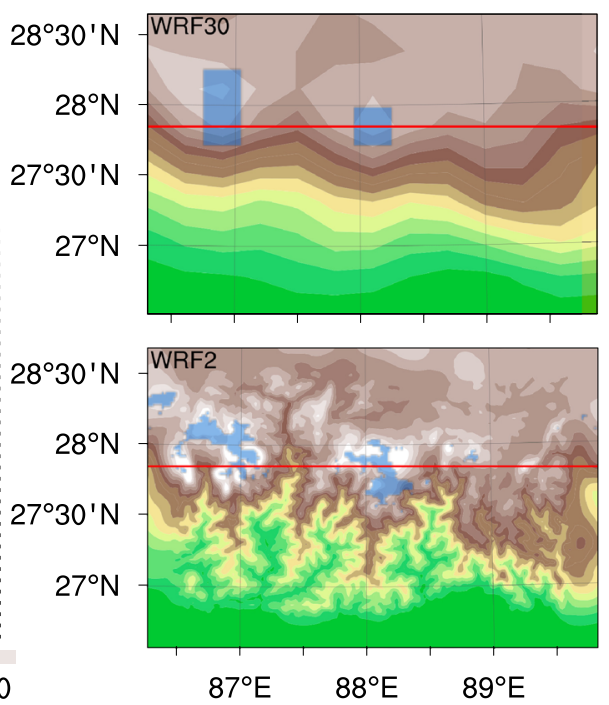

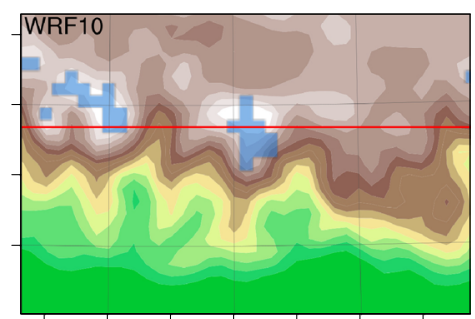

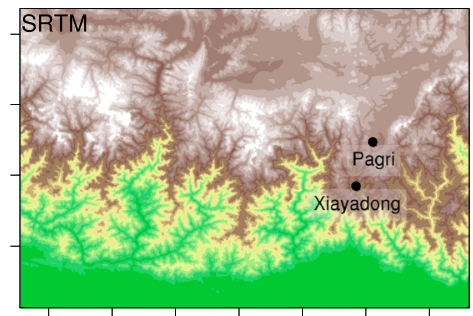

$87^{\circ} \mathrm{E} \quad 88^{\circ} \mathrm{E} \quad 89^{\circ} \mathrm{E}$
Fig. 1 a Maps of the three nested WRF domains with the water area marked as blue. Black dots show available observation sites within D2. b Topography of the target region (D3) at three resolutions-30 $\mathrm{km}$ (WRF30), $10 \mathrm{~km}$ (WRF10), and $2 \mathrm{~km}$ (WRF2) - and the reference from the Shuttle Radar Topography Mission (SRTM; 30 m reso- lution) with two currently available rain gauges marked and labeled: Pagri and Xiayadong. Blue shaded denotes grids with land use type classified as "ICE/SNOW". Red line indicates the southern border of the TP defined herein
The very complex-terrain D3 is of particular concern, and the detailed analyses are carried out for D3. To avoid confusion between model domains and horizontal resolutions, the WRF model's output in the three different horizontal resolutions $(30,10$, and $2 \mathrm{~km}$ ) will be named WRF30, WRF10, and WRF2 respectively. Compared to the real topography presented by the Shuttle Radar Topography Mission (SRTM) of $30 \mathrm{~m}$ resolution, WRF30 heavily smooths the topography while WRF2 represents more details of SRTM (Fig. 1b). Information loss due to coarse resolution is not limited to the topography but also land use classification (figure not shown), which has important effects on the representation of meso-microscale processes. Despite the fact that the coarser model runs provide lateral boundary conditions for runs with finer resolution, each of them can still be seen as an independent simulation. WRF30 refines the forcing data from the reanalysis and may therefore capture larger-scale processes. WRF10 is expected to represent most mesoscale features and explicitly resolve gravity wave drag (GWD). Processes of scale smaller than $10 \mathrm{~km}$, such as mountain-valley circulation, glacier wind, and turbulent form orographic drag (TOFD), are expected to be represented in WRF2. As the resolution dependency is of our particular interest, it is necessary to give freedom to each simulation of the different resolutions. Thus, the analysis nudging is not applied, to avoid overly influencing the results with the lateral boundary forcing, although it is a sophisticated way to prevent the downscaling model from unrealistic drift and improve simulation performance (Storch et al. 2000; Pohl and Crétat 2014).

\subsubsection{Selection of model physics and other technical notes}

The setup of physical parameterization schemes (detailed in Table 1) overall refers to the reference experiment in Maussion et al. (2011), which has been also prescribed for the High Asia Refined (HAR) data (Maussion et al. 2014). Note that cumulus parameterization was turned off in the highest-resolution, convection-permitting WRF2 (e.g., Molinari and Dudek 1992; Weisman et al. 1997). Sensitivity to physical parameterization schemes is beyond the scope of this study, though it could be a critical factor for precipitation bias in models (e.g., Maussion et al. 2011; Gao et al. 2017). Thus, little attention was paid to optimizing the setup of model physics. Regarding the steep terrain specified, we did take some additional actions to ensure the model's performance following various simulation studies for complex terrain (e.g., Mölg and Kaser 2011; Collier et al. 2013), i.e., enlarging the number of grids for specified boundary value nudging, adding an damping layer to control reflection from the upper boundary, and applying positive-definite explicit 6th order diffusion (Knievel et al. 2007). The ERA-interim reanalysis $\left(\right.$ at $0.75^{\circ}$ ) (Dee et al. 2011), produced by the European Centre for Medium-Range Weather Forecasts, provides lateral boundary conditions and sea surface temperature (both updated every $6 \mathrm{~h}$ ) for WRF30. The WRF 
Table 1 WRF configuration

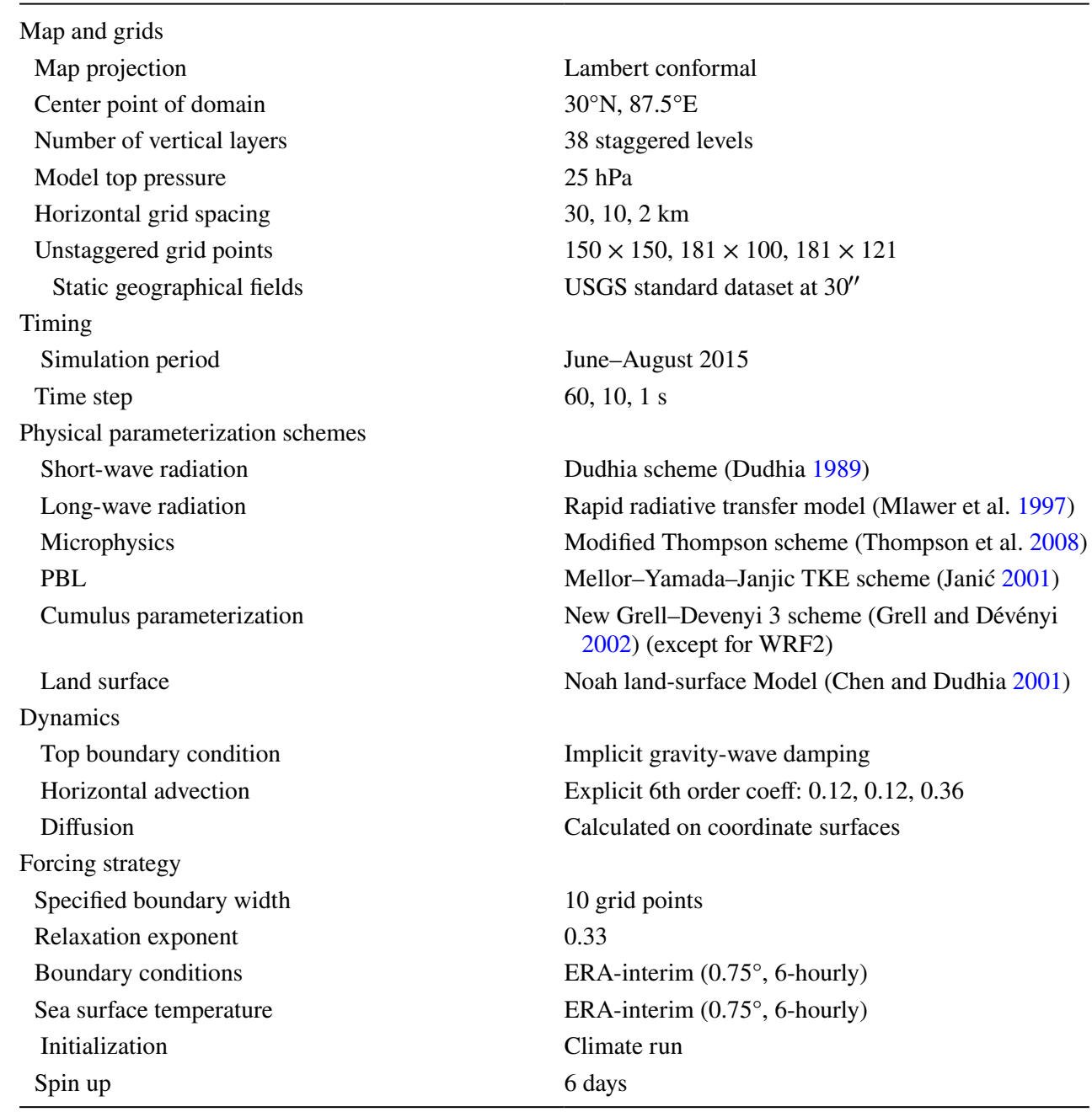

run was carried out for a matured summer monsoon period (June-August; JJA), accompanied with a great proportion of annual precipitation (e.g., Su et al. 2013). Specifically, the simulation began at 00:00 UTC on 26 May 2015 and ended at 00:00 UTC on 1 September 2015, with the first 6 days regarded as the model spin-up time. According to our checking, the choice of first 6 days as spin-up time is safe to ensure the equilibrium between the boundary conditions and the model dynamics. Ensemble runs are usually needed to derive a robust result. However, this technique was not implemented, as we considered that each simulating day can be regarded as an ensemble member (i.e., JJA mean as the ensemble mean) to investigate resolution dependency of simulated WVT in a matured monsoon season.

In order to further isolate the impact of topographic representation on the WVT simulation, two additional simulations (named WRF10_TOPO30 and WRF2_TOPO10) were performed with the same configurations as in the original runs but with topography data derived from the coarser resolutions; i.e., WRF10_TOPO30 has same configurations as WRF10 but with topography data that has a single value for each nested $3 \times 3$ grids as the corresponding grid of WRF30, and similar for WRF2_TOPO10.

\subsection{Data for reality check}

A reality check based on multiple data could assist the interpretation of model results. The resolution dependency of simulated WVT is of particular interest; however, there is currently no direct observations that can be used to verify model simulations, because observing WVT is difficult (e.g., Gutowski et al. 1997 and references therein). The routine measurements of weather stations include precipitation and near-surface wind speed. Understanding the potential sources of precipitation bias in models is the ultimate objective of this study. As wind transports water vapor, we conducted comparisons between model results and in situ measurements for mean wind speed at $10 \mathrm{~m}$ height and JJA cumulative precipitation. We collected these observational data from "Global Summary of the Day" provided by NOAA's National Centers for Environmental Information (NCEI). Sites only with complete records over the simulation period (JJA, 2015) are selected. It is a pity that 
there is only one site (Pagri, behind the Yadong valley) available within the target region D3 (Fig. 1b) plus one rain gauge in Xiayadong (a village within the Yadong Valley) installed and maintained by the authors. To make a compensation, we therefore extended the comparison to D2, within which there are totally 20 NCEI stations. Of note is that we calculated the relative precipitation bias rather than absolute one, in view of there is huge difference of precipitation between over the southern Himalayan slopes and the flattening inner TP. The relative bias a variable $x$ is calculated as follows:

$\frac{x_{\text {sim }}-x_{o b s}}{x_{o b s}} \times 100 \%$

where $x_{\text {sim }}$ and $x_{o b s}$ are of simulation and observation, respectively.

With regard to spatial pattern, simulated precipitation was also compared to satellite data of the Global Precipitation Measurement (GPM) mission (Hou et al. 2014), which is designed as a next-generation space-based measuring system and the successor of the successful Tropical Rainfall Measuring Mission (TRMM). GPM has been shown to outperform TRMM in the southern TP region (Xu et al. 2017). We used its monthly product of Level-3 IMERG (the Integrated Merged MultisatellitE Retrievals for GPM) Final Run (research products) version $04 \mathrm{D}$, which has the spatial resolution of $0.1^{\circ}$ close to $10 \mathrm{~km}$.

\subsection{Assessment method for WVT}

Curio et al. (2015) assessed the climatology of WVT towards the TP based on HAR analysis, providing a good example for analyzing WVT over a complex region using model data. Following the methodology therein, the analysis was performed for the original model levels directly (without interpolation to pressure levels) to avoid information loss, and the data from the boundary grids (10-grid width) removed to avoid lateral boundary effects. In addition, water vapor content (WV) and horizontal wind in the model were examined to reveal processes which were poorly represented by the model due to insufficient resolution. WV and WVT at each of 37 unstaggered $\sigma$ levels were calculated using the following formulas:

$W V=\rho r$

and

$W V T=v_{h} \rho r$

with

$\rho=\frac{p}{R_{d}(1+0.61 r) T}$

where $\rho$ is the air density $\left(\mathrm{kg} \mathrm{m}^{-3}\right), r$ the mixing ratio for water vapor $\left(\mathrm{kg} \mathrm{kg}^{-1}\right), v_{h}$ the horizontal wind vector (m $\mathrm{s}^{-1}$ ), $p$ the pressure (pa), $R_{d}$ the gas constant, and $T$ the air temperature (K). The Himalayan range is almost east-west oriented within D3, which is considered the southern border of the TP. Here we specify it at grids paralleled $\mathrm{x}$-direction and around $27^{\circ} 50^{\prime} \mathrm{N}$ (Fig. 1b). Therefore, WVT towards the TP was quantified at the vertical cross section along this border, and only the $v$ (northward) component was of concern. To obtain the total column of WV (i.e., PW) and of WVT $\left(W V T_{c o l}\right)$, we additionally integrated WV and WVT along the metric $z$ coordinate from surface to the top of the $\sigma$ levels using the rectangle method as follows:

$P W=\int_{z=z_{s f c}}^{z=z_{\text {top }}} \rho r \delta z$

and

$W V T_{c o l}=\int_{z=z_{s c}}^{z=z_{\text {top }}} v_{h} \rho r \delta z$

where $\delta z$ is the thickness of each $\sigma$ level (m).

\section{Results and discussion}

\subsection{Reality check of model simulation}

\subsubsection{Comparison for precipitation}

Figure 2a shows the comparison of JJA cumulative precipitation between the in situ measurement and the simulations with different resolutions. All the model results overestimate precipitation, on an average around 200\%. In terms of absolute magnitude, the overestimation has lager values for sites located at the southern part of D2 than those of the north. In terms of relative bias (as shown in 2a), however, large overestimation (with an average $>250 \%$ ) appears at the northern sites whereas small overestimation (with an average $<150 \%$ ) at the southern sites within D2, as there is a relatively large amount of precipitation at the southern Himalayan slopes and their south. WRF10 outperforming WRF30 is commonly observed at sites in the northern D2 (i.e., the TP). As revealed from the only two available rain gauges within D3, WRF2 significantly reduces precipitation bias compared to the coarser-resolution simulations.

Figure 3 provides a comparison of spatial pattern of JJA cumulative precipitation between the model results and GPM data. In general, GPM shows that high values of JJA cumulative precipitation are found in the southeast part of D3 and gradually decrease northward and westward. Overall, this pattern is captured by WRF10 and WRF2. In WRF30, the center of high precipitation turns northward, near the top of the Himalayas. Moreover, WRF10 and WRF2 provide small-scale features that are not presented by GPM. 

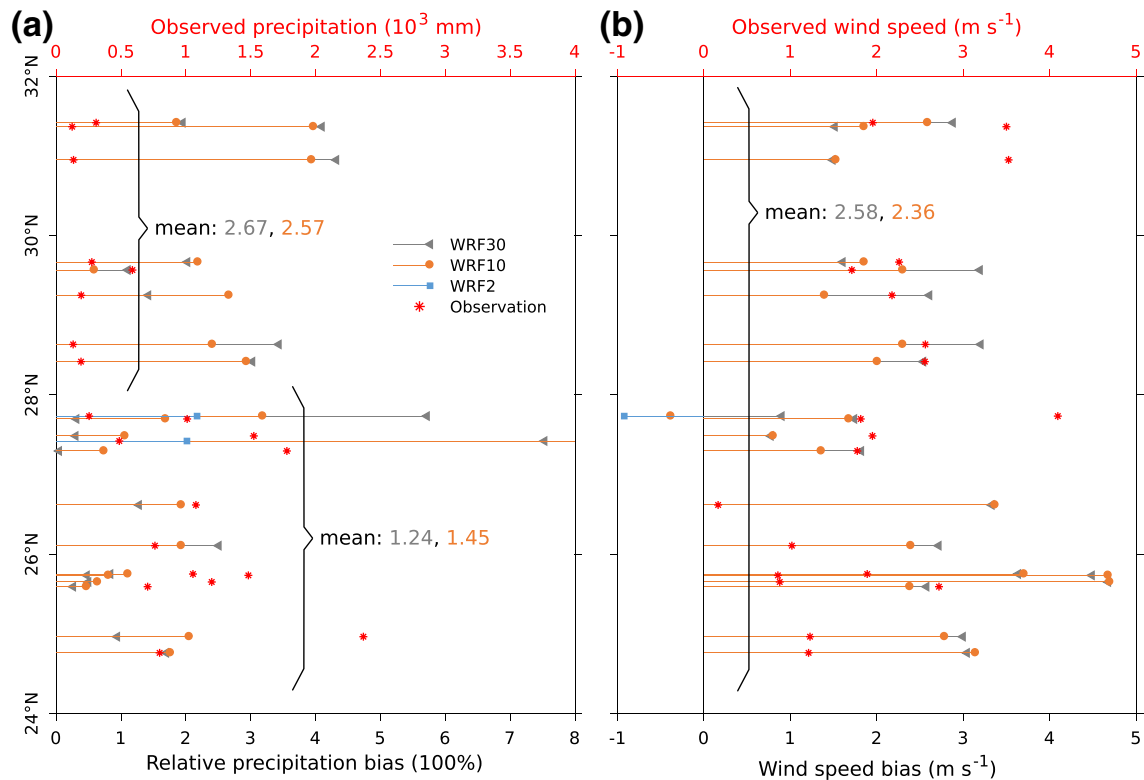

(c)

Fig. 2 Comparison of model results against in situ observations with respect to latitude. a Relative bias of JJA cumulative precipitation (bottom axis) and observed presipitation (top axis). b Bias of JJA mean wind speed at $10 \mathrm{~m}$ height (bottom axis) and observed

wind speed (top axis). c Terrain height difference to observation sites for corresponding model grids. Mean values (grey for WRF30 and orange for WRF10) over certain latitudinal ranges (denoted by close braces) are given following the close braces
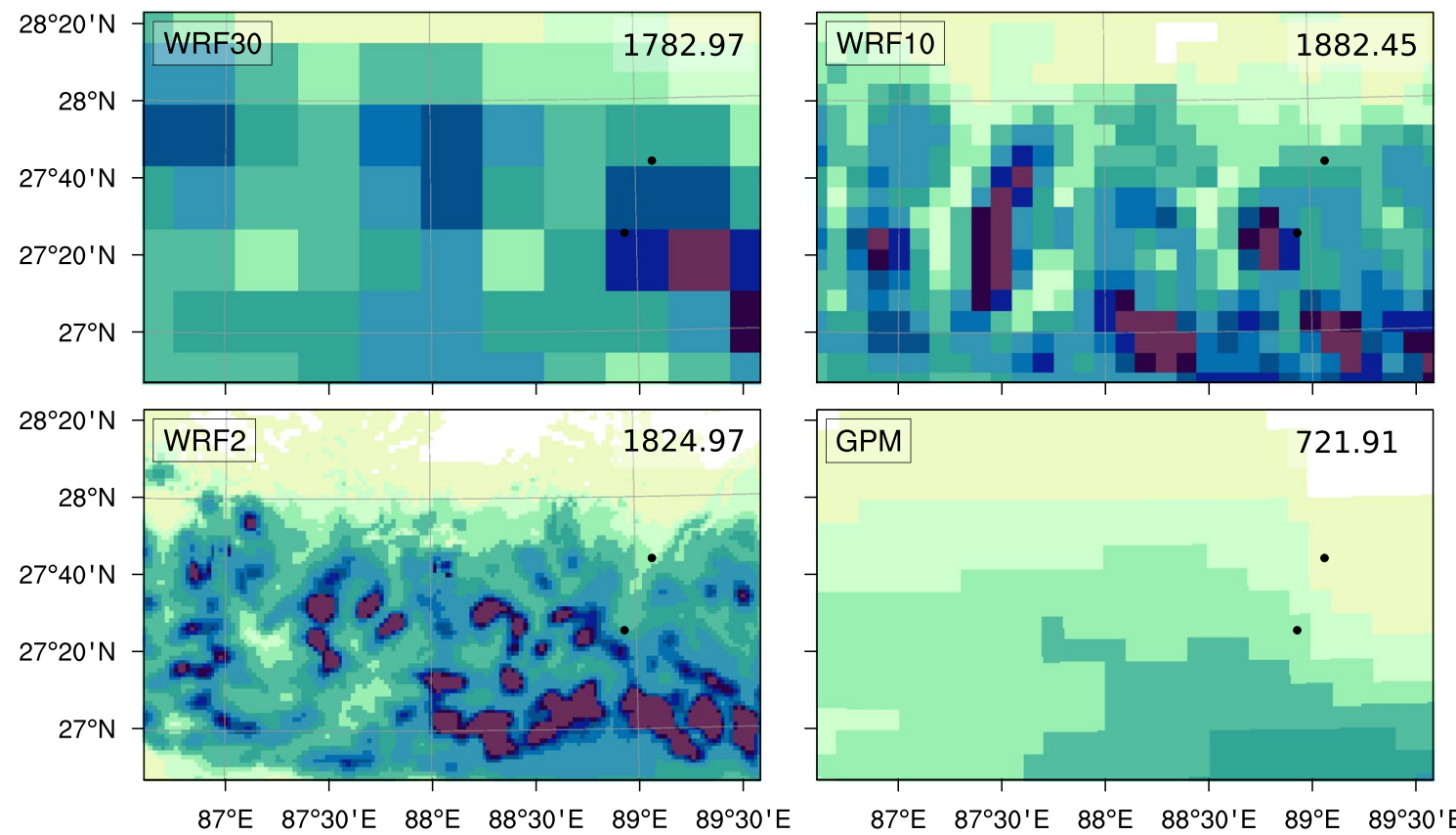

Precipitation $(\mathrm{mm})$

$\begin{array}{llllllllllll}250 & 500 & 750 & 1000 & 1500 & 2000 & 2500 & 3000 & 3500 & 4000 & 4500 & 5000\end{array}$

Fig. 3 Spatial pattern of JJA cumulative precipitation for WRF30, WRF10, WRF2, and GPM over D3, with domain average provided at upperright conner. Two currently available rain gauges within D3 are marked as black dots 
Referring to the zonal average as from the perspective of precipitation along the slopes, as shown in Fig. 4, WRF model with a finer (coarser) resolution among the three produces more (less) precipitation over the lower southern slopes and less (more) over the regions within the TP (i.e., to the north of the Himalayan top).

\subsubsection{Comparison for near-surface wind speed}

Like for precipitation, near-surface wind speed is overestimated (with an average bias of 2.6 and $2.4 \mathrm{~m} \mathrm{~s}^{-1}$ for WRF30 and WRF10, respectively) by model results at all the sites other than the only observation (at Pagri) available within D3 (Fig. 2b). At Pagri, a negative bias of wind speed is detected for WRF10 and WRF2; however, a large uncertainty relating to this comparison is expected as there is only one observational site for D3. Overall, WRF10 outperforms WRF30 for wind speed simulation, especially for the sites with latitude within the range from $27^{\circ} \mathrm{N}$ to $30^{\circ} \mathrm{N}$.

\subsubsection{Uncertainties associated with the reality check}

According to above comparisons, notable discrepancies exhibit between the model results and the in situ observations that are available at a limited number of sites. Understanding the sources of uncertainties, for both model results and observations, is necessary and useful.

With regard to the simulations of this study, uncertainties may come from the forcing data (e.g. Gao et al. 2017), inappropriate setup of vertical levels, selection of parameterization schemes (e.g. Gao et al. 2017; Maussion et al. 2011) and/or dynamic options (e.g. Collier et al. 2015; Kusaka et al. 2005). For instance, Collier et al. (2015) found that computing horizontal diffusion in physical space rather than along coordinate surfaces improves their precipitation simulation over a complex terrain, indicating potential rooms

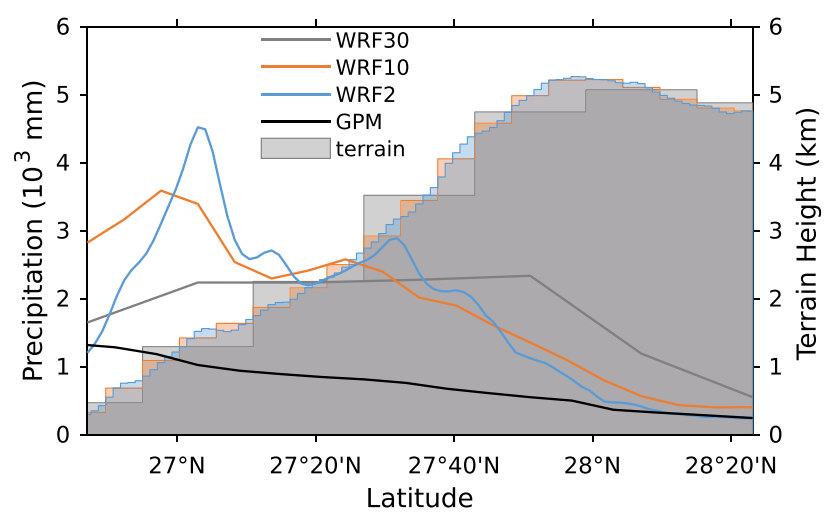

Fig. 4 Zonal average of JJA cumulative precipitation for WRF30, WRF10, WRF2, and GPM. Shaded areas show the corresponding terrain represented by different resolutions to optimize our model configuration. For another instance, the explicit treatment of convection can play a key role to improve precipitation simulation (e.g. Collier and Immerzeel 2015; Norris et al. 2016; Sato et al. 2008; Karki et al. 2017). Nevertheless, cases of this treatment with either overestimation or underestimation have reported in previous studies. Our simulations with the three resolutions show overall the similar amount of precipitation for the whole domain of D3 despite the differences in spatial heterogeneity (Fig. 3). It is interesting to note that convection-permitting WRF2 does not provide significantly more details of such a spatial heterogeneity than WRF10.

This high spatial heterogeneity of precipitation, meanwhile, lacks an absolute reference due to the scarce observations. Further, there are also issues linked to their poor spatial representativeness due to the complex terrain and the fact that few, if at all, stations are located at mountain peaks and ridges. A study of precipitation characteristics in highmountain areas of the Nepal Himalaya (Higuchi et al. 1982) found that precipitation over mountain peaks and ridges can be around 4-5 times larger than that at valley bottoms. This example indicating large uncertainty can be induced by the limited spatial representativeness of precipitation measurements over this complex-terrain region. Additionally, unreliable snowfall measurements may also degrade the quality of observations from high-elevation stations (e.g. Norris et al. 2016), where snowfall may occurs in summer as well.

The satellite data GPM has been proved to have a poor performance over complex terrain (Xu et al. 2017). Indeed, the high heterogeneity of precipitation over mountainous areas documented in Higuchi et al. (1982) is exhibited in both WRF10 and WRF2 but not in GPM (Fig. 3).

The fact that model result is for the average over a grid cell while the in situ observation is for a point can also bring about uncertainties. Huge mismatch is found between the real elevation of the Xiayadong station and that of the model's nearest grid cell, especially for coarse resolutions (Fig. 2c), which could be a probable reason for the extra precipitation bias of WRF10 at Xiayadong against that observed.

\subsubsection{Facts revealed by the reality check}

It is currently not available to present a solid validation of model results in view of the above discussion. Attempt to optimizing the configuration of WRF may improve some features of simulation, but this is beyond the scope of the current study. We noticed two facts delivered from the reality check: (1) the finer-resolution simulations produced more precipitation over the lower southern Himalayan slopes whereas less over regions within the TP where "wet bias" gets diminished to a certain extent; and (2) the finerresolution simulations overall presents weaker wind speed 
than the coarser ones. With respect to these facts, further analyses on the resolution dependency of simulated WVT were conducted.

\subsection{Resolution dependency of simulated WVT}

\subsubsection{On the total column WVT}

The left column of Fig. 5 shows the JJA mean of WVT within the cross-section along the southern border of the TP around $27^{\circ} 50^{\prime} \mathrm{N}$, of which the positive values (northward) mean transport towards the TP. Overall, the total column WVT crossing through the transect for WRF30, WRF10, and WRF2 is $33.1,28.0$, and $26.0 \mathrm{~kg} \mathrm{~m}^{-1} \mathrm{~s}^{-1}$, respectively; i.e., compared to WRF2, WRF30 brings $27.5 \%$ more water vapor to the TP while a moderate addition of $7.9 \%$ is estimated for WRF10. However, these values could depend on how we define the border. According to our investigation by moving the border to different locations ( $30 \mathrm{~km}$ southward, $30,60,90$ and $120 \mathrm{~km}$ northward, among which the last is to the north of D3), however, such resolution dependency is found to remain essentially the same (figures not shown). Indeed, this resolution dependency can also be backed up by the inter-comparison of spatial pattern (Fig. 6) and zonal average (Fig. 7a) of total column WVT. Even for the whole D3, there is such a resolution dependency for domainaveraged northward total column WVT. According to the assessment of Curio et al (2015, Table 1 and 2 therein), less summertime WVT crossing through the central Himalayas (cross-sections 4-5 in their tables) for the finer HAR was presented, supporting our results.

In contrast to the difference of WVT through the border (top of the Himalayas), similar values of WVT are found at the lower southern Himalayan slopes for the three resolutions (Fig. 7a). This points to an additional convergence of water vapor in finer-resolution simulations compared to coarser ones, explaining the larger amount of precipitation over the southern slopes (Fig. 4). Meanwhile, the reverse causality is true from a conservation point of view; more water vapor removal (in form of precipitation) over the southern slopes leads to less WVT towards the TP.

\subsubsection{Impact on precipitation bias}

According to our experiment with WRF, the positive precipitation bias in simulations with coarser resolutions can be


$10^{-2} \mathrm{~kg} \mathrm{~m}^{-3}$

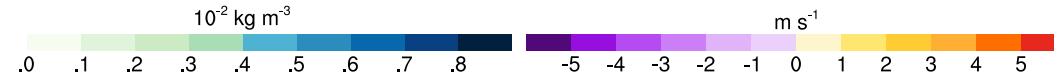

Fig. 5 JJA mean of water vapor transport (left), water vapor content (middle), and $v$ wind (right) within the cross section (along the south border of the TP defined herein, i.e., red lines in Fig. 1) for WRF30, WRF10, and WRF2. Section mean value of total column water vapor transport, content (i.e., precipitable water), and lowest-10-level mean $v$ wind is given at bottom-left conner of each subplot. Grey shaded areas show the terrain 


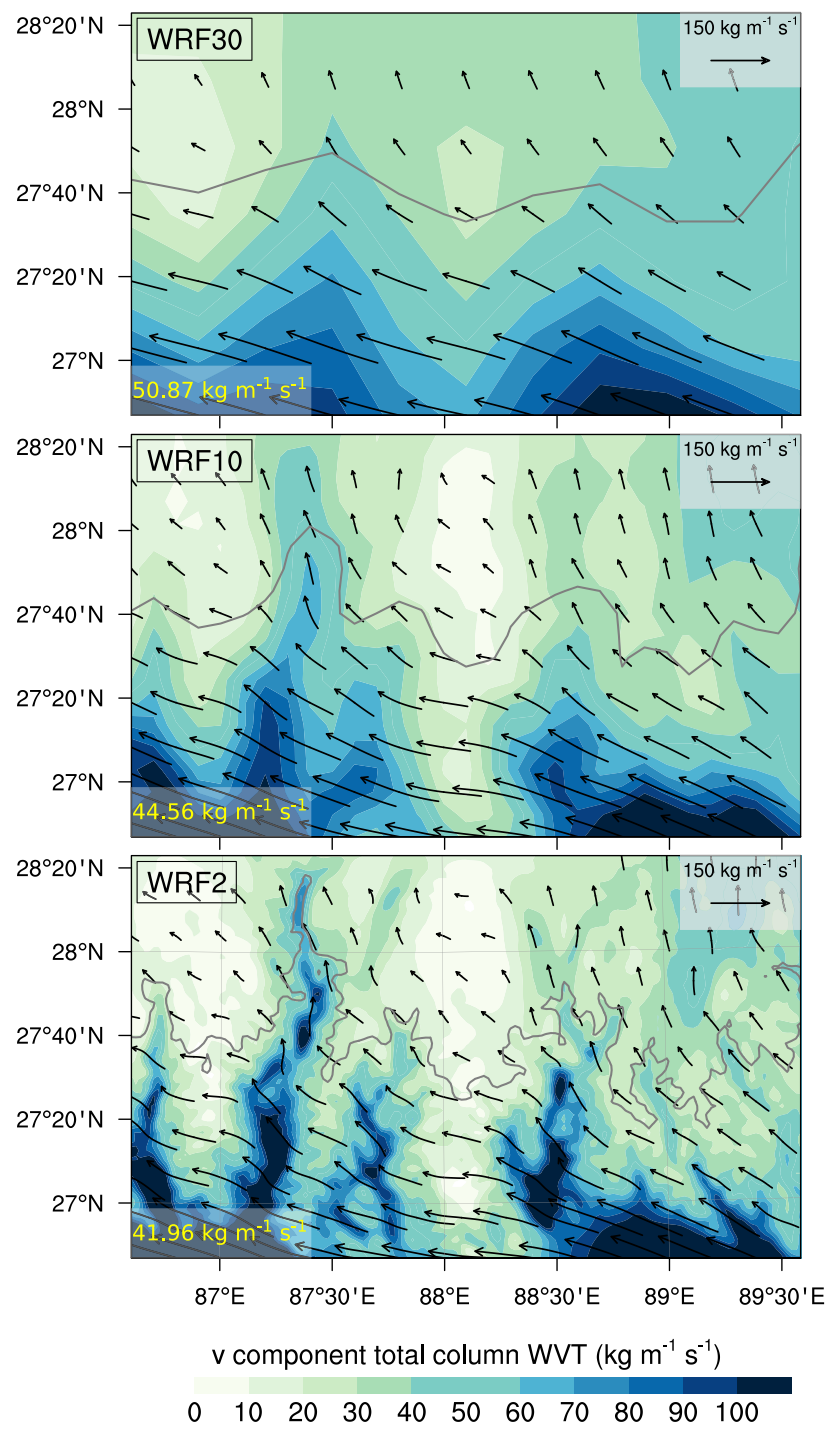

Fig. 6 Spatial pattern of total column water vapor transport (vector) and its $v$ component (color) for WRF30, WRF10, and WRF2, with domain average of $v$ component provided at bottom-left conner. Grey curves represent elevation of $4000 \mathrm{~m}$ plausibly linked to the excessive WVT towards the TP, as the WVT provides a major moisture source for the precipitation over the TP in summer (Feng and Zhou 2012; Zhang et al. 2017). Nevertheless, it is difficult to quantify the contribution from the excessive WVT caused by insufficient resolution to the wet bias in models due to the fact that no WVT measurements are available. Moreover, additional areas of uncertainty comes from following facts: (1) the tendency of PW over a certain area is a function of WVT convergence, rather than WVT; (2) the whole TP is not covered in D3 with a resolution of $2 \mathrm{~km}$ due to limited computational resources; and (3) the performance of microphysics and/or cumulus scheme can also affect simulated formation of cloud and precipitation via the transformation rate from water vapor to precipitation. Besides errors in the external sources of moisture, precipitation bias over the TP may also be contributed by representation errors of land surface model in WRF, as $63.2 \%$ of water is estimated to be provided by local moisture recycling (Curio et al. 2015). However, to estimate this part of precipitation bias contribution, realistic simulation of WVT is firstly required because land surface may react to it.

\subsubsection{Topographical barrier and channeling effects on WVT}

In addition to total column WVT, our results also reveal some other features of WVT with respect to different model resolutions. As shown in the left column of Fig. 5, dominant WVT takes place at lower levels and, therefore, its zonal distribution is associated with the terrain height represented by the model. For WRF30, the terrain is so smoothed that the mountain bodies can hardly be revealed from the figure. As a result, the Himalayas across the domain from west to east serve as pathways rather than barriers for WVT. By contrast, the regional heterogeneity of WVT (Fig. 6), i.e., barrier effect of high mountains and channeling effect of valleys, is exhibited in the modeling results from WRF2, which definitely benefits from the improvement of topographic representation. And, to some extent, WRF10 simulates the overall zonal WVT distribution as well as WRF2 does, except for a few details. This indicates a resolution of around $10 \mathrm{~km}$ (a)

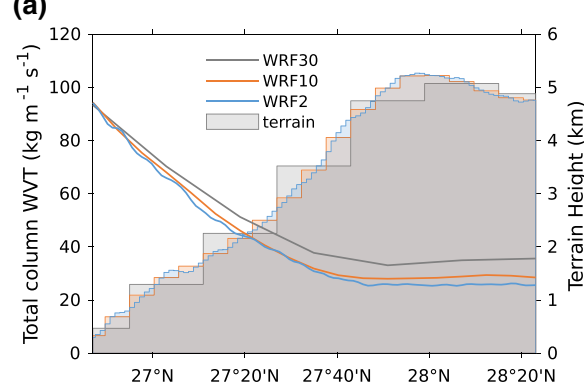

(b)

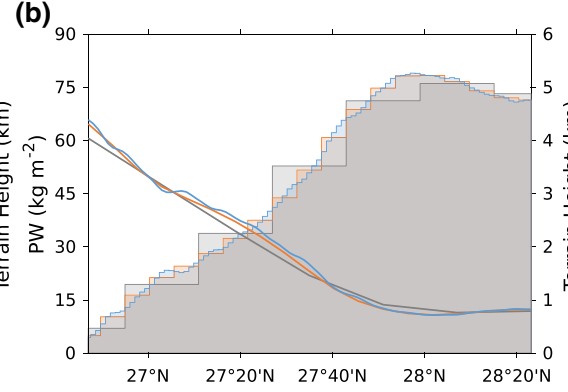

(c)

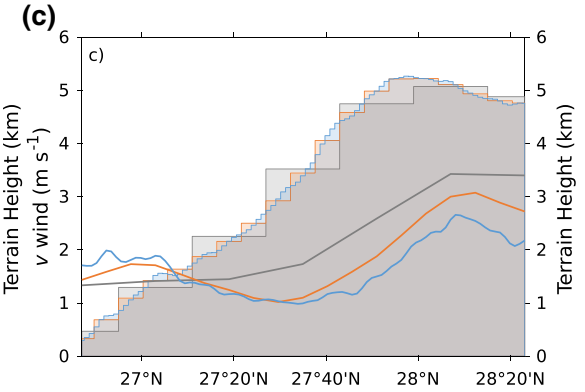

Fig. 7 Similar to Fig. 4, but for total column water vapor transport (a), precipitable water vapor (b), and lowest-10-level mean $v$ wind (c) 
is likely to be the minimum required by a model to reasonably represent topographical barrier and channeling effects on WVT, as they regulate the spatial pattern of water vapor content which in turn has impacts on local precipitation.

\subsection{Behind the resolution dependency of simulated WVT}

Processes of varying spatial scales are explicitly resolved by models when increasing the resolution. Thus, simulated WVT over a complex terrain is expected to be improved with finer resolutions. For instance, orographic precipitation over the southern Himalayan slopes can only be wellcaptured by models with the finest resolution of the three $(25,5$, and $1 \mathrm{~km})$ used in Karki et al. (2017). Such orographic precipitation would reserve part of the water vapor, leading to less WVT being transported towards the TP. To identify processes that are behind the changed WVT and precipitation, we initially examined $\mathrm{WV}$ and $v$ wind (i.e., the two independent terms of WVT computation). It is clear that changes in the representation of meridional wind play a more important role in the WVT patterns shown in Fig. 5, as differences in atmospheric humidity are relatively minor outside of deep valley areas. Because the lowest 10 model levels (below approximately $2 \mathrm{~km}$ ) almost account for $80 \%$ of the total column WVT, the lowest-10-level mean of $v$ wind is inter-compared among the three resolutions. For the section mean as shown in the right column of Fig. 5, the simulated lowest-10-level mean of $v$ wind is $2.6,1.9$, and $1.5 \mathrm{~m} \mathrm{~s}^{-1}$ for WRF30, WRF10, and WRF2, respectively. Similarly, moving the cross section within a certain range does not challenge the resolution dependency of simulated meridional wind.

Types of orographic drag including GWD and TOFD directly influence the wind field and are of importance to complex-terrain regions (e.g., Beljaars et al. 2004). Sufficient resolution or subgrid parameterization for models is required to resolve such drag processes so that wind field can be realistically simulated. Among the simulations, WRF10 is expected to nearly fully resolve GWD; and WRF2, further, should be able to explicitly resolve TOFD. Efforts were made to isolate impact of topographic representation on WVT and wind simulation, by conducting additional simulations (WRF10_TOPO30 and WRF2_TOPO10; see Sect. 2), as shown in Fig. 8. Compared to the results of Fig. 5, degrading the topographic representation indeed yielded stronger WVT and wind speed; especially, a large difference (49.5 vs. $28.0 \mathrm{~kg} \mathrm{~m}^{-1} \mathrm{~s}^{-1}$ ) was found between WRF10_TOPO30 and WRF10, indicating GWD is crucial for the complex terrain. WRF simulations generally overestimate the near-surface wind speed according comparison to the limited observations. Refining the model resolution from 30 to $10 \mathrm{~km}$ weakens simulated wind significantly, although there may still be rooms to further diminish the positive bias as indicated by WRF2.

Besides the direct orographic drag, other processes associated with heterogeneous surface forcing that cannot be well represented due to resolution issues, such as glacier wind and mountain-valley circulation, can also affect the simulation of wind field. Indeed, negative value (i.e., southward) corresponding to glacierized areas (of grids with land use type classified as "ICE/SNOW"; Fig. 1) in the right column
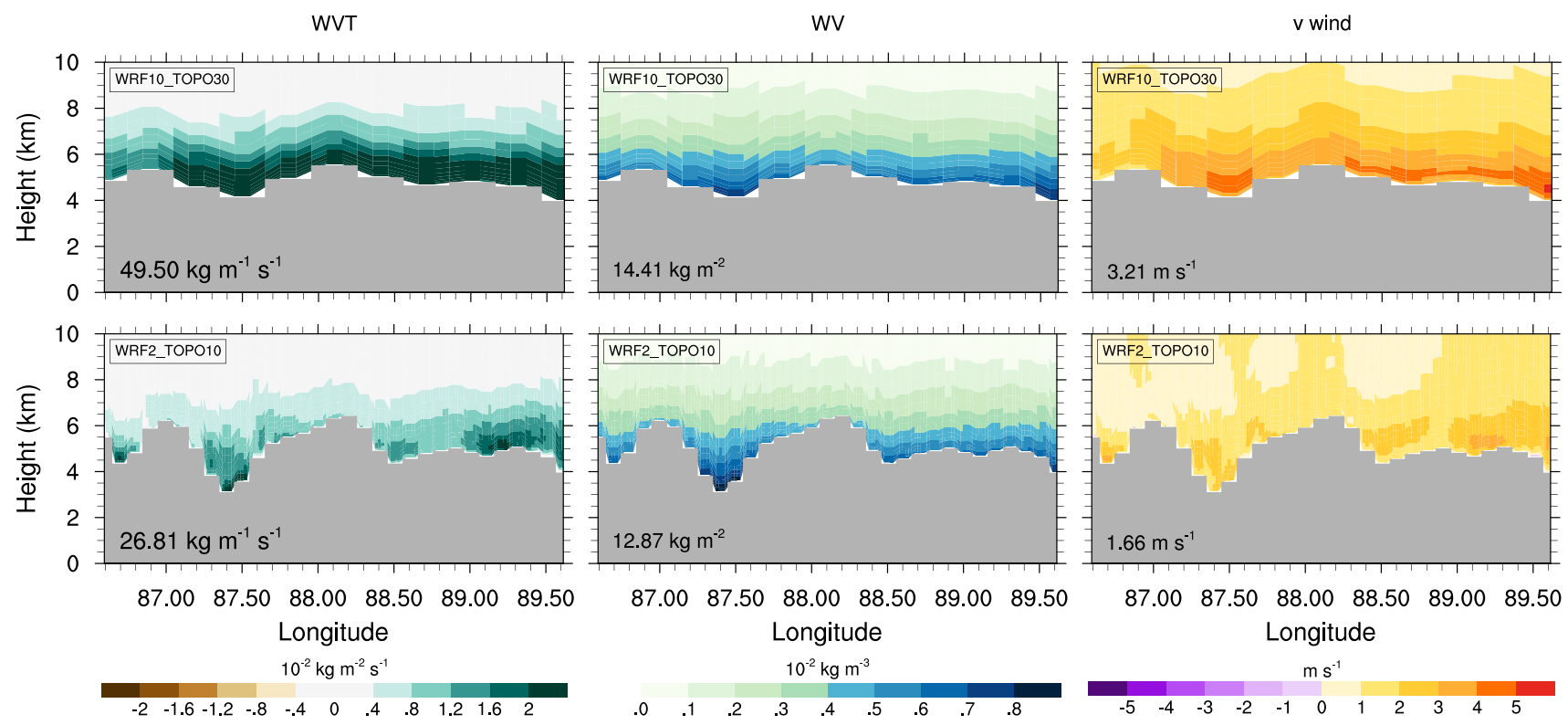

Fig. 8 Similar to Fig. 5, but for WRF10_TOPO30 and WRF2_TOPO10 
of Fig. 5 possibly reflects downslope glacier wind, which is not captured by WRF30 but by finer-resolution simulations, especially WRF2. This may also account for, at least partly, the resolution dependency of simulating wind and WVT.

The success of HAR (Maussion et al. 2014) illustrates that a fine-resolution regional modeling covering a long period and high spatial resolution is direly needed and useful as forcing for hydroclimate studies over the TP. Our results indicate that a coarser resolution can lead to stronger summertime WVT crossing the Himalayas, which in turn may cause the wet biases in precipitation over the TP. Although WRF2 produced relatively weak WVT and a small amount of precipitation over the part of the southern TP, which likely lead to reduce the wet biases over the TP, it is however not operationally feasible to carry out a long-term run for the entire TP with such a convection-permitting resolution. A good compromise seems to lie with a resolution around $10 \mathrm{~km}$. According to above analyses, a significant weakening of both simulated wind speed and WVT, which may be linked to less wet biases in precipitation over the $\mathrm{TP}$, is found when the resolution is changed from 30 to 10 $\mathrm{km}$. WRF2 further weakens simulated wind speed and WVT from WRF10 to a lesser extent, which may have to do with the fact that TOFD is explicitly resolved in WRF2. Indeed, by inducing the TOFD scheme developed by Beljaars et al. (2004) to WRF with a resolution of $0.25^{\circ}$, Zhou et al. (2017) were able to improve the simulation of both near-surface and upper-air wind fields over the TP. The variance of subgridscale orography is extremely high (up to $50000 \mathrm{~m}^{2}$ ) over the slopes of the Himalayas for a $10 \mathrm{~km}$ grid spacing (figure not shown); this points to the necessity of considering subgrid drag with such a resolution.

\section{Concluding remarks}

In view of the common wet bias in current climate models over the TP, it is necessary to determine the sources of such wet bias and find solutions. In this study, we investigated the resolution dependency of simulated WVT over the central Himalayas and its impact on precipitation bias over the TP by analyzing WRF simulations over a summer season with horizontal resolutions of 30,10 , and $2 \mathrm{~km}$.

According to the comparison with limited in situ observations and GPM satellite data, overestimation of precipitation commonly exists in the WRF simulations. As a reality check, the comparison meanwhile provides an direction to diminish the positive precipitation bias over the TP by increasing model resolution. This is especially true for convection-permitting WRF2, as it produced the least amount of precipitation over the areas within TP.

The coarser-resolution simulations produce less precipitation over the southern Himalayan slopes and more intensive
WVT towards the TP, leading to a larger wet bias in precipitation over the TP. This resolution dependency of the simulated WVT is reflected mostly in wind field. A finer resolution is corresponding to lower wind speed and WVT simulated, of which the former is closer to observations, probably because of the better capacity to explicitly resolve orographic drag (e.g., GWD, TOFD) over the complex terrain as well as other relevant processes (e.g., glacier wind, mountain-valley circulation) that are associated with heterogeneous surface forcing. Particularly, the most significant decrement of the simulated wind speed and WVT was found from WRF30 to WRF10, suggesting a resolution around 10 $\mathrm{km}$ or so to be a good compromise to reasonably and meanwhile efficiently simulate WVT in the study region.

Acknowledgements This work was supported by the National Natural Science Foundation of China (Grant 91537210), Swedish VR, VINOVVA, STINT, BECC, MERGE, and SNIC through S-CMIP. The authors wish to express thanks to Jun Qin, Yingying Chen, Yan Wang, Lin Ouyang, and Lazhu for their efforts on the station setup at Xiayadong. Dataset of "Global Summary of the Day" provided NCEI (Formerly the National Climatic Data Center; NCDC) is available at https://www.ncdc.noaa.gov/isd/products. GPM satellite precipitation products are available at https://pmm.nasa.gov/data-access/downloads/ gpm. Funding was provided by Vetenskapsrådet and Swedish Foundation for International Cooperation in Research and Higher Education.

Open Access This article is distributed under the terms of the Creative Commons Attribution 4.0 International License (http://creativecommons.org/licenses/by/4.0/), which permits unrestricted use, distribution, and reproduction in any medium, provided you give appropriate credit to the original author(s) and the source, provide a link to the Creative Commons license, and indicate if changes were made.

\section{References}

Beljaars A, Brown AR, Wood N (2004) A new parametrization of turbulent orographic form drag. Q J R Meteorol Soc 130(599):13271347. https://doi.org/10.1256/qj.03.73

Bookhagen B, Burbank DW (2010) Toward a complete himalayan hydrological budget: Spatiotemporal distribution of snowmelt and rainfall and their impact on river discharge. J Geophys Res Earth Surf. https://doi.org/10.1029/2009JF001426

Chen F, Dudhia J (2001) Coupling an advanced land surfacehydrology model with the Penn State-NCAR MM5 modeling system. Part I: model implementation and sensitivity. Mon Weather Rev 129(4):569-585. https://doi. org/10.1175/1520-0493(2001)129\%3c0569:CAALSH\%3e2.0 . $\mathrm{CO} ; 2$

Chin HNS, Caldwell PM, Bader DC (2010) Preliminary study of California wintertime model wet bias. Mon Weather Rev 138(9):3556-3571. https://doi.org/10.1175/2010MWR3409.1

Codron F, Sadourny R (2002) Saturation limiters for water vapour advection schemes: impact on orographic precipitation. Tellus A 54(4):338-349. https://doi.org/10.1034/j.1600-0870.2002.01265.x

Collier E, Immerzeel WW (2015) High-resolution modeling of atmospheric dynamics in the Nepalese Himalaya. J Geophys Res Atmos 120(19):9882-9896. https://doi.org/10.1002/2015JD023266 
Collier E, Mölg T, Maussion F, Scherer D, Mayer C, Bush A (2013) High-resolution interactive modelling of the mountain glacieratmosphere interface: an application over the Karakoram. Cryosphere 7(3):779-795. https://doi.org/10.5194/tc-7-779-2013

Collier E, Maussion F, Nicholson LI, Mölg T, Immerzeel WW, Bush ABG (2015) Impact of debris cover on glacier ablation and atmosphere glacier feedbacks in the Karakoram. Cryosphere 9(4):16171632. https://www.the-cryosphere.net/9/1617/2015/

Curio J, Maussion F, Scherer D (2015) A 12-year high-resolution climatology of atmospheric water transport over the Tibetan Plateau. Earth Syst Dyn 6(1):109. https://doi.org/10.5194/esd-6-109-2015

Danard M, Zhang Q, Kozlowski J (1993) On computing the horizontal pressure gradient force in sigma coordinates. Mon Weather Rev 121(11):3173-3183. https://doi. org/10.1175/1520-0493(1993)121\%3c3173:OCTHPG\%3e2.0 .CO; 2

Dee D, Uppala S, Simmons A, Berrisford P, Poli P, Kobayashi S, Andrae U, Balmaseda M, Balsamo G, Bauer P et al (2011) The ERA-Interim reanalysis: configuration and performance of the data assimilation system. Q J R Meteorol Soc 137(656):553-597. https://doi.org/10.1002/qj.828

Dudhia J (1989) Numerical study of convection observed during the winter monsoon experiment using a mesoscale twodimensional model. J Atmos Sci 46(20):3077-3107. https://doi. org/10.1175/1520-0469(1989)046\%3c3077:NSOCOD\%3e2.0 $\mathrm{CO} ; 2$

Feng L, Zhou T (2012) Water vapor transport for summer precipitation over the Tibetan Plateau: multidata set analysis. J Geophys Res Atmos. https://doi.org/10.1029/2011JD017012

Gao Y, Xu J, Chen D (2015) Evaluation of WRF mesoscale climate simulations over the Tibetan Plateau during 1979-2011. J Clim 28(7):2823-2841. https://doi.org/10.1175/JCLI-D-14-00300.1

Gao Y, Xiao L, Chen D, Chen F, Xu J, Xu Y (2017) Quantification of the relative role of land-surface processes and large-scale forcing in dynamic downscaling over the Tibetan Plateau. Clim Dyn 48(5-6):1705-1721. https://doi.org/10.1007/s00382-016-3168-6

Grell GA, Dévényi D (2002) A generalized approach to parameterizing convection combining ensemble and data assimilation techniques. Geophys Res Lett. https://doi.org/10.1029/2002GL015311

Gutowski WJ Jr, Chen Y, Ötles Z (1997) Atmospheric water vapor transport in NCEP-NCAR reanalyses: comparison with river discharge in the central United States. Bull Am Meteorol Soc 78(9):19571969. https://doi.org/10.1175/1520-0477(1997)078\%3c1957:AW VTIN\%3e2.0.CO;2

Higuchi K, Ageta Y, Yasunari T, Inoue J (1982) Characteristics of precipitation during the monsoon season in high-mountain areas of the Nepal Himalaya. Hydrol Asp Alp High Mount Areas 138:21-30

Hou AY, Kakar RK, Neeck S, Azarbarzin AA, Kummerow CD, Kojima M, Oki R, Nakamura K, Iguchi T (2014) The global precipitation measurement mission. Bull Am Meteorol Soc 95(5):701-722. https://doi.org/10.1175/BAMS-D-13-00164.1

Janić ZI (2001) Nonsingular implementation of the Mellor-Yamada level 2.5 scheme in the NCEP Meso model. Technical report, National Centers for Environmental Prediction, Office Note No. 437

Ji Z, Kang S (2013) Double-nested dynamical downscaling experiments over the Tibetan Plateau and their projection of climate change under two RCP scenarios. J Atmos Sci 70(4):1278-1290. https://doi.org/10.1175/JAS-D-12-0155.1

Karki R, Hasson S, Gerlitz L, Schickhoff U, Scholten T, Böhner J (2017) Quantifying the added value of convection-permitting climate simulations in complex terrain: A systematic evaluation of WRF over the Himalayas. Earth Syst Dyn 8(3):507-528. https:// doi.org/10.5194/esd-8-507-2017
Knievel JC, Bryan GH, Hacker JP (2007) Explicit numerical diffusion in the WRF model. Mon Weather Rev 135(11):3808-3824. https:// doi.org/10.1175/2007MWR2100.1

Kusaka H, Crook A, Knievel JC, Dudhia J (2005) Sensitivity of the wrf model to advection and diffusion schemes for simulation of heavy rainfall along the baiu front. SOLA 1:177-180. https://doi. org/10.2151/sola.2005-046

Lenton TM, Held H, Kriegler E, Hall JW, Lucht W, Rahmstorf S, Schellnhuber HJ (2008) Tipping elements in the Earth's climate system. Proc Nat Acad Sci 105(6):1786-1793. https://doi. org/10.1073/pnas.0705414105

Ma J, Wang H, Fan K (2015) Dynamic downscaling of summer precipitation prediction over Cina in 1998 using WRF and CCSM4. Adv Atmos Sci 32(5):577. https://doi.org/10.1007/s00376-014-4143-y

Maussion F, Scherer D, Finkelnburg R, Richters J, Yang W, Yao T (2011) WRF simulation of a precipitation event over the Tibetan Plateau, China - an assessment using remote sensing and ground observations. Hydrol Earth Syst Sci 15(6):1795-1817. https://doi. org/10.5194/hess-15-1795-2011

Maussion F, Scherer D, Mölg T, Collier E, Curio J, Finkelnburg R (2014) Precipitation seasonality and variability over the Tibetan Plateau as resolved by the High Asia Reanalysis. J Clim 27(5):1910-1927. https://doi.org/10.1175/JCLI-D-13-00282.1

Mehran A, AghaKouchak A, Phillips TJ (2014) Evaluation of CMIP5 continental precipitation simulations relative to satellite-based gauge-adjusted observations. J Geophys Res Atmos 119(4):16951707. https://doi.org/10.1002/2013JD021152

Mlawer EJ, Taubman SJ, Brown PD, Iacono MJ, Clough SA (1997) Radiative transfer for inhomogeneous atmospheres: RRTM, a validated correlated-k model for the longwave. J Geophys Res Atmos 102(D14):16,663-16,682. https://doi.org/10.1029/97JD00237

Mölg T, Kaser G (2011) A new approach to resolving climate-cryosphere relations: Downscaling climate dynamics to glacier-scale mass and energy balance without statistical scale linking. J Geophys Res Atmos. https://doi.org/10.1029/2011JD015669

Molinari J, Dudek M (1992) Parameterization of convective precipitation in mesoscale numerical models: a critical review. Mon Weather Rev 120(2):326-344. https://doi. org/10.1175/1520-0493(1992)120\%3c0326:POCPIM\%3e2.0 . $\mathrm{CO} ; 2$

Mueller B, Seneviratne S (2014) Systematic land climate and evapotranspiration biases in CMIP5 simulations. Geophys Res Lett 41(1):128-134. https://doi.org/10.1002/2013GL058055

Mughal MO, Lynch M, Yu F, McGann B, Jeanneret F, Sutton J (2017) Wind modelling, validation and sensitivity study using weather research and forecasting model in complex terrain. Environ Model Softw 90:107-125. https://doi.org/10.1016/j.envsoft.2017.01.009

Norris J, Carvalho LM, Jones C, Cannon F, Bookhagen B, Palazzi E, Tahir AA (2016) The spatiotemporal variability of precipitation over the Himalaya: evaluation of one-year WRF model simulation. Clim Dyn. https://doi.org/10.1007/s00382-016-3414-y

Pohl B, Crétat J (2014) On the use of nudging techniques for regional climate modeling: application for tropical convection. Clim Dyn 43(5-6):1693-1714. https://doi.org/10.1007/s00382-013-1994-3

Sato T, Yoshikane T, Satoh M, Miura H, Fujinami H (2008) Resolution dependency of the diurnal cycle of convective clouds over the Tibetan Plateau in a mesoscale model. J Meteorol Soc Jpn Ser II 86:17-31. https://doi.org/10.2151/jmsj.86A.17

Shen M, Piao S, Cong N, Zhang G, Jassens IA (2015) Precipitation impacts on vegetation spring phenology on the Tibetan Plateau. Glob Change Biol 21(10):3647-3656. https://doi.org/10.1111/ gcb. 12961

Skamarock WC, Klemp JB, Dudhia J, Gill DO, Barker DM, Duda MG, Huang XY, Wang W, Powers JG (2008) A description of the advanced research WRF version 3. Technical report, NCAR/ TN-475+STR. https://doi.org/10.5065/D68S4MVH 
Su F, Duan X, Chen D, Hao Z, Cuo L (2013) Evaluation of the global climate models in the CMIP5 over the Tibetan Plateau. J Clim 26(10):3187-3208. https://doi.org/10.1175/JCLI-D-12-00321.1

Su F, Zhang L, Ou T, Chen D, Yao T, Tong K, Qi Y (2016) Hydrological response to future climate changes for the major upstream river basins in the Tibetan Plateau. Glob Planet Change 136:82-95. https://doi.org/10.1016/j.gloplacha.2015.10.012

Thompson G, Field PR, Rasmussen RM, Hall WD (2008) Explicit forecasts of winter precipitation using an improved bulk microphysics scheme. Part II: implementation of a new snow parameterization. Mon Weather Rev 136(12):5095-5115. https://doi. org/10.1175/2008MWR2387.1

Tian L, Yao T, MacClune K, White J, Schilla A, Vaughn B, Vachon R, Ichiyanagi K (2007) Stable isotopic variations in west China: a consideration of moisture sources. J Geophys Res Atmos. https:// doi.org/10.1029/2006JD007718

von Storch H, Langenberg H, Feser F (2000) A spectral nudging technique for dynamical downscaling purposes. Mon Weather Rev 128(10):3664-3673. https://doi. org/10.1175/1520-0493(2000)128\%3c3664:ASNTFD\%3e2.0 .CO;2

Wang Y, Yang K, Pan Z, Qin J, Chen D, Lin C, Chen Y, La Z, Tang W, Han M et al (2017) Evaluation of precipitable water vapor from four satellite products and four reanalysis datasets against GPS measurements on the Southern Tibetan Plateau. J Clim 30(15):5699-5713. https://doi.org/10.1175/JCLI-D-16-0630.1

Weisman ML, Skamarock WC, Klemp JB (1997) The resolution dependence of explicitly modeled convective systems. Mon Weather Rev 125(4):527-548. https://doi. org/10.1175/1520-0493(1997)125\%3c0527:TRDOEM\%3e2.0 . $\mathrm{CO} ; 2$
Xu R, Tian F, Yang L, Hu H, Lu H, Hou A (2017) Ground validation of GPM IMERG and TRMM 3B42V7 rainfall products over southern Tibetan Plateau based on a high-density rain gauge network. J Geophys Res Atmos 122(2):910-924. https://doi. org/10.1002/2016JD025418

Xu X, Lu C, Shi X, Gao S (2008) World water tower: an atmospheric perspective. Geophys Res Lett. https://doi. org/10.1029/2008GL035867

Yang K, Ye B, Zhou D, Wu B, Foken T, Qin J, Zhou Z (2011) Response of hydrological cycle to recent climate changes in the Tibetan Plateau. Clim Change 109(3):517-534. https://doi.org/10.1007/ s10584-011-0099-4

Yao T, Thompson L, Yang W, Yu W, Gao Y, Guo X, Yang X, Duan K, Zhao H, Xu B et al (2012) Different glacier status with atmospheric circulations in Tibetan Plateau and surroundings. Natu Clim Change 2(9):663-667. https://doi.org/10.1038/nclimate1580

Yu R, Li J, Zhang Y, Chen H (2015) Improvement of rainfall simulation on the steep edge of the Tibetan Plateau by using a finitedifference transport scheme in CAM5. Clim Dyn 45(9-10):2937. https://doi.org/10.1007/s00382-015-2515-3

Zhang C, Tang Q, Chen D (2017) Recent changes in the moisture source of precipitation over the Tibetan Plateau. J Clim 30(5):1807-1819. https://doi.org/10.1175/JCLI-D-15-0842.1

Zhang Y, Li J (2016) Impact of moisture divergence on systematic errors in precipitation around the Tibetan Plateau in a general circulation model. Clim Dyn 47(9-10):2923-2934. https://doi. org/10.1007/s00382-016-3005-y

Zhou X, Yang K, Wang Y (2017) Implementation of a turbulent orographic form drag scheme in WRF and its application to the Tibetan Plateau. Clim Dyn. https://doi.org/10.1007/ s00382-017-3677-y 